$\begin{array}{cccc}\text { S sciendo } & \text { International Conference KNOWLEDGE-BASED ORGANIZATION } \\ \text { Vol. XXVII } & \text { No } 2 & 2021\end{array}$

\title{
TRENDS IN MODERN SPORTS TRAINING - BASIS OF PHYSICAL TRAINING FOR THE CADETS FROM THE COMBAT BRANCH
}

\author{
Fabiana MARTINESCU-BĂDĂLAN, Crenguța-Mihaela MACOVEI \\ "Nicolae Bălcescu" Land Forces Academy, Sibiu, Romania \\ martinescu_fabiana@yahoo.com, mihaela.macovei1@gmail.com
}

\begin{abstract}
The training process as well as the adaptation of the body is a multifactorial process. This means that the factors can vary from the morpho-functional and genetic characteristics of the subjects to the patterns of a selected training program, dosed and loaded by the person who leads the instructive-educational process. The body's adaptation to these factors is directly related to the methods and means used. During the training process it is necessary to follow a series of principles and rules, which help and ensure the proper conduct of the training system for athletes.
\end{abstract}

\section{Keywords: physical training, athletes, combat cadets}

\section{Introduction}

Training is multi-factorial in nature; as such the attempt is to exploit known principles of physics, physiology, and psychology in order to maximize the effects of the training stimulus. The training process is vitally concerned with the positive enhancement of performance - therefore the process must provide:

- An appropriate stimulus for adaptation;

- An appropriate means for assessing progress (monitoring);

- Adequate means, in addition to the sets and reps (i.e., stimulus) including restrecovery phases, psychological reenforcement, daily nutrition, supplements, sleep, etc. so that recovery is optimized [1]. The training process tries to make the subjects reach their genetic limits, in other words the training is not just a mere recreational exercise.

Today we can no longer think of talking about sports performance without mentioning the importance of physical training associated with it.

\section{Characteristics and requirements of sports training}

The modern requirements of sports training can be considered rules as a result of the practical experience gained by specialists in various sports. Depending on the degree of generality, on their application in solving different typical or atypical situations, the training requirements acquire more or less value of principle [2].

There is evidence that the manner and phases in which training is presented to the subject, by the leader of the educational instructional process, can have a major impact on the outcome of performance. This mainly refers to the concepts of periodization, programming and modeling of training programs for different types of training.

In order to obtain good performances, their ability to solve the specific problems that 
appear during the competition must be developed, by creating similar situations in the training lessons.

Training should be recognized as a process which prepares an athlete, technically, tactically, psychologically, and physically for the highest possible levels of performance [3].

Some requirements of sports training were specified over the years by many authors in sport field. These were adapted to the military environment and the results were the following:

- Improving the training as well as directing it towards performance-this means the evolution of the training factors depending on the specifics of the weapon or the sport practiced.

- Supporting the complexity of training. This aspect signifies a desideratum in modern physical training. The focus on only a part of the training would lead to an incomplete, limited development of the individual, so that it could no longer achieve the proposed performance objectives.

- Durability of training. The progressive planning of the training in order to obtain the sports form plays an important role in the performance sports training. The expression of sportsmanship can be controlled by a number of indicators, such as: obtaining the planned (maximum) results in competitions, fulfilling or exceeding the scales of control tests, ease or fluency of technical executions, high physical and mental tone, as well as other factors of an objective and subjective nature [4].

- Adapting the body to the level of demand. This adaptation is of progressive type and is "determined by the practical rule that highlights that a standard stimulus, with certain intensity, loses its quality if its values do not increase progressively. This involves periodically changing the value of one stimulus or changing it with another" [5].

- The type of effort will be programmed to a maximum or high intensity. The best results are obtained when the subjects are well adapted to the maximum efforts. "Training through intense and maximum efforts has become a decisive requirement in the training of performance athletes, but this requirement must not be in contradiction with the requirement of gradual training for the submission of these types of efforts" [6].

We have adapted other types of training characteristics, very important in fact, for the "combat cadets" for whom this article is actually relevant.

- "The training process is complex, multifactorial and interdisciplinary, in its elaboration, guidance and control participating, along with the fundamental sports-coach couple, and scientists, doctors, organizers and technicians"[7]. In the military field this can be reduced to the active participation of military instructors, physical education teachers, doctors as well as specialists in the field to the gradual and rigorous planning and programming of future combat cadets for their missions.

- Training is a process with an organized and well-structured character planned and conducted according to specific, own and complex laws, principles and rules of the competent parties - biological, psychic and socio-human; it aims at the development of physical skills together with intellectual and affective ones.

- It is desired to adapt the body of individuals to intense and extreme efforts, as well as to maintaining this state of readiness for as long as possible.

- "It permanently preserves the characteristics of praxiological activity, all the approaches of athletes, coaches and scientist being oriented towards obtaining the highest performances"[8].

- Training is an instructive-educational activity with a strong pedagogical side in the desire to have effect on the consciousness of the individual in order to shape it towards performance.

- It is based on the mechanisms of selfregulation, the individual using all means to 
adapt to the new conditions as well as achieving the proposed objectives.

- "Combat cadets" are individuals endowed both physically and mentally, who must permanently adapt and improve their physical abilities for the successful fulfillment of missions; these aspects become possible through training.

- Training directs the entire preparation process in order to obtain the best results, improving the capacity for effort, improving physical abilities, education and emotional stability.

- There are different types of training, depending on the level of training, age, gender, types of effort and goals.

- "Although it aims to increase the progressive capacity to maximize performance, sports training remains permanently subordinated to the fundamental requirement of human personality development, in full harmony with the needs of the society in which it lives" [9].

A major component of a training session is planning it. This concerns the understanding of both the developmental and conceptual aspects of the training process [10].

\section{Current trends in sports training}

High-volume programs generally have a greater influence on body composition, enhancement of muscle cross-sectional area, and work capacity factors than do low-volume higher intensity programs. In contrast, high-intensity programs have a greater influence on maximum strength, peak power, and velocity compared to lowintensity programs [11].

Modern trends in sports training are oriented in the following directions:

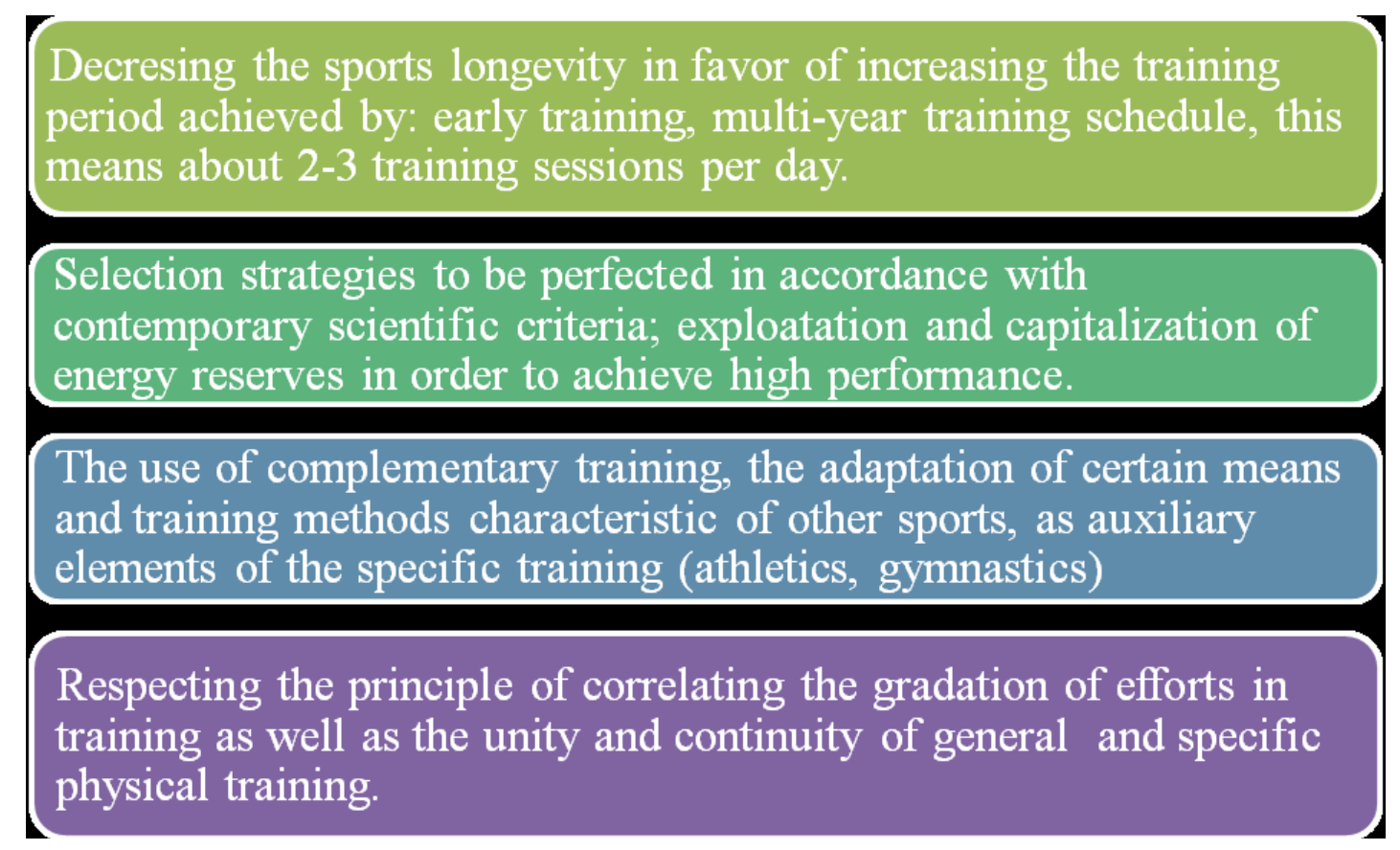




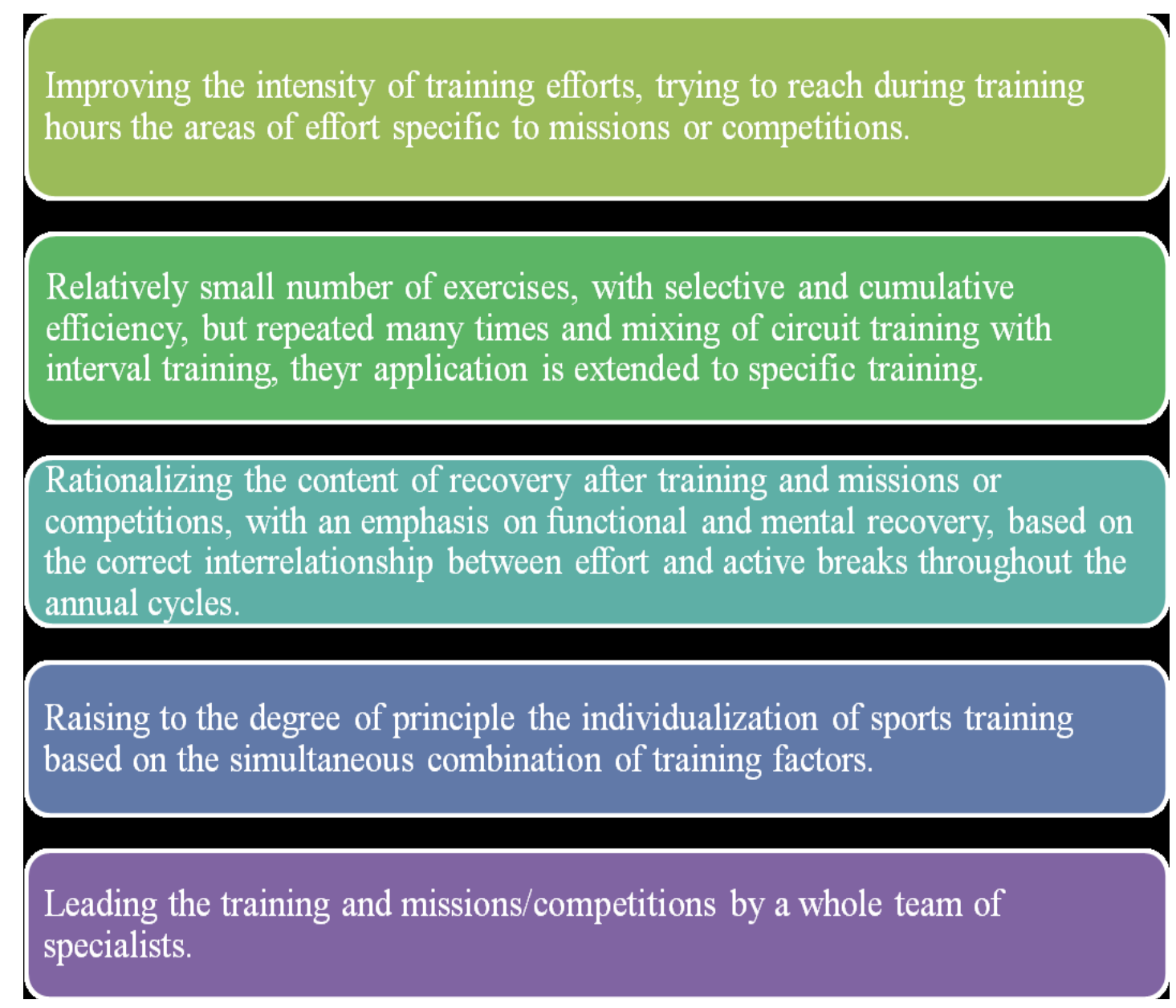

\section{Conclusions}

Military personnel- the combat cadets by excellence - are professional athletes. The "soldier" job is mainly one which involves having specific physical characteristics. The success that combat soldiers want to have in missions is similar to that of the professional athletes, because in both fields the physical training is the one that can determine the success. This kind of training must be specific to the tasks and objectives to be performed.

Thus, we cannot have trained fighters without a basis of training, without a periodization, an application of both rational and objective principles.

This article tries to present in fact the desire to understand more aspects related to physical training in relation to performance but also the opening to a new scientific approach, with clear planning directions to train professional "combat cadets".

These situations are missing due to the fact that innovation and prospecting are not necessarily areas in which those who deal directly with the physical training of individuals are comfortable. Instructors and specialized teachers often dedicate themselves to the routine of the programs they master without imagining for a moment the exploration of new aspects related to the improvement of training methods and means. Concluding all the above, in this article we want to promote fact-based trends that support the many ideas in the field. It is an important aspect in bringing to light new features and trends in the field just to be able to apply them in daily practice. 


\section{References List}

[1] DeWeese B.H., Hornsby G., Stone M., Stone M.H. The training process: Planning for strength-power training in track and field.Part1: Theoretical aspects. Journal of Sport and Health Science; 2015; 4:308-317.

[2] Aubert F. La preparation physique et sa dimension prophylactique. 2005 https://www.creps-aquitaine.fr/IMG/pdf/Approches_prophylactiques_F_Aubert.pdf

[3] Epstein D. The sports gene: inside the science of extraordinary athletic performance NewYork, NY: Penguinbooks; 2014.

[4] Dragnea A., Teodorescu M, S. Teoria Sportului. FEST; Bucureşti; 2002; 216-221.

[5] Dragnea A., Teodorescu M, S., op.cit.

[6] Dragnea A., Teodorescu M, S., op.cit.

[7] Nicu, A., (1993) - Antrenamentul sportiv modern, Ed. Editis, Bucureşti, p.105.

[8] Nicu, A., op.cit.

[9] Nicu, A., op.cit.

[10] Ribeiro A.S, Schoenfeld B.J, Fleck S.J, Pina F.L.C., Nascimiento N.A., Cyrino E:S., Effects Of Traditional And Pyramidal Resistance Training Systems On Muscular Strength, Muscle Mass, And Hormonal Responses In Older Women: A Randomized Crossover Trial. The Journal of Strength and Conditioning Research, 2017:1888-1896 DOI: 10.1519/JSC. 0000000000001653

[11] DeWeese B.H., Hornsby G., Stone M., Stone M.H. op.cit. 